\title{
The development of a biorefining strategy for the production of biofuel from sorghum milling waste
}

Ahmed El-Imam, Amina M. ${ }^{1,2 *}$, Greetham, Darren ${ }^{3}$, Du, Chenyu ${ }^{3}$, Dyer, Paul S. ${ }^{1}$

1: School of Life Sciences, University of Nottingham, NG7 2RD, United Kingdom

2: Faculty of Life Sciences, University of Ilorin, P.M.B. 1515, Ilorin, Nigeria

3: School of Applied Sciences, University of Huddersfield, HD1 3DH, United Kingdom

* Corresponding author: amkmusty@yahoo.com

\begin{abstract}
The potential of using sorghum milling waste for the development of a biorefining strategy for the production of bioethanol was investigated. Both red and white sorghum were processed using a traditional Nigerian wet-milling process to sorghum flour. The sorghum milling waste, sorghum bran, was hydrolysed using both enzymatic and dilute acid hydrolysis to produce a generable fermentation feedstock. The hydrolysates were subsequently investigated for fermentative biofuel production. Following a hydrolysis step, a medium containing $\sim 61 \mathrm{~g} / \mathrm{L}$ glucose was obtained. Trace presence of inhibitors was detected in the hydrolysates and sufficient nitrogen content to support microorganism growth and bioethanol production. In test bioethanol production experiments using the sorghum milling waste derived hydrolysates only, $24.35 \mathrm{~g} / \mathrm{L}$ bioethanol was produced by a yeast Kluyveromyces marxianus, equivalent to a yield of 0.15 gram bioethanol per gram of sorghum milling waste.
\end{abstract}

\section{KEY WORDS:}

Sorghum milling waste; Bioethanol; sorghum bran; Biorefinery; Hydrolysis; Yeast Screening

\section{Introduction}

In line with the desire to attain the sustainable development goal of renewable energy (SDG 7) renewable fuels are currently being used as alternatives to petroleum-based fuels in transportation. The introduction of renewable fuels decreases the negative environmental effects caused by the combustion of fossil fuels [1-3]. Bioethanol is currently the most commonly used and most important liquid biofuel. The annual production of bioethanol reached 51 billion liters in 2007 and increased to 85 billion litres in 2011 [4-5].

The first generation bioethanol is produced using glucose and starch [6-7]. However, the first generation biofuel production is unsustainable because it competes with the food cultivation uses of arable land, negatively impacts biodiversity, may contribute to deforestation and desertification, and has a high water footprint [8-9]. Consequently, efforts have been directed towards the development of second-generation bioethanol processes using feedstocks comprising agricultural, industrial and food processing wastes collectively known as lignocellulosic biomass. These feedstocks are rich in complex carbohydrates, are not considered to be food products, and have lower water footprint than energy crops and third generation biofuels from algae $[8,10]$. Biomass-based ethanol is the only liquid transportation fuel that does not exacerbate the greenhouse effect [4]. However, carbohydrates present in lignocellulosic biomass (i.e. cellulose and hemicellulose) are embedded within lignin, and are recalcitrant to hydrolysis into sugars due to their crystalline structure [11]. Thus a pretreatment process is required prior to enzymatic hydrolysis, such as dilute acid pretreament, alkaline pretreatment, or steam explosion pretreatments, to break lignocellulosic raw materials down to their monomeric 
sugars [12-14]. The generated sugars may then be fermented into bioethanol by several microorganisms including Saccharomyces cerevisiae, Scheffersomyces stipites, Candida shehatae and Zymomonas mobilis [4,15]. The pretreatment step increases the complexity and cost of the process, thus creating a need to develop simple, inexpensive processes to readily convert renewable feedstock into sugars for the production of higher-value products [16]. The pretreatment step can also lead to the release of compounds that can inhibit downstream chemical processes and/or inhibit the growth of microorganisms.

The wastes accumulated from the processing of cereals such as the brans of maize, rice, sorghum and wheat have also been widely used in bioprocesses [17-19]. These biomass types also contain less recalcitrant carbohydrates such as starch, which makes them potentially easier to break down into monomeric sugars. Sorghum (Sorghum bicolor (L.) Moench) is an annual cereal which belongs to the grass family Poaceae. It grows well in harsh environments where other crops grow poorly or produce poor yields and is the second most important cereal after maize in Africa [20]. Industrial dry-milling of sorghum for starch production produces waste bran, which has been explored as a feedstock, for bioethanol production [21,22]. The most common traditional processing method of sorghum in Nigeria involves steeping, wet-milling and sieving. The bran removed by this process is usually discarded or fed to animals as a low-value feed.

Nigeria is the second-largest producer of sorghum globally, with 6.5 million metric tonnes produced in the 2016/2017 agricultural year [23]. In 2018, the Federal Government of Nigeria announced plans to set up a $\$ 50$ billion biofuel industry equity fund to develop the domestic biofuel sector [24], facilitating the global shift towards renewable fuels. The International Energy Agency reported that bioethanol would remain the dominant biofuel even by 2030 [25]. Hence, the use of sorghum bran as a cheap and widely available feedstock for ethanol production would considerably improve the sorghum value-chain and thus economic conditions in growing countries; in addition to other accruable benefits such as the reduction in wastes discarded into the environment and lowered greenhouse gas emissions.

Even though it has been utilised for enzyme production [26,27] and bioremediation [28], with the exception of the work of Corredor et al., [22] the huge potential of sorghum bran (SB) for bioethanol production has not been sufficiently explored. Several sorghum varieties contain phenolic compounds such as tannins [29], and detannification significantly reduces peak and final viscosities of sorghum grain mashes. However, higher viscosities were shown to result in higher ethanol yields [30]. Thus, the presence of tannins in sorghum could potentially contribute to efficient ethanol production from its bran. In addition, since it has been reported that sorghum starch-based fermentation resulted in similar ethanol yields as maize [31], this work aims to investigate the suitability of sorghum bran to support yeast growth and metabolism by developing relatively inexpensive ways to produce a generic sugar-rich medium, sorghum bran hydrolysate, and subsequently determine the potential of this medium for ethanol production. Finally, the potential for bioethanol production using sorghum milling waste in Nigeria was assessed.

\section{Materials and methods}

\subsection{Sorghum and sorghum-based biorefining process}

There are several varieties of sorghum in Nigerian markets but they are generally classified as white or red sorghum with little and inconsistent variation in price. The red and white varieties of sorghum (Sorghum bicolor) grains were obtained from local 
markets in Ilorin, Nigeria, and processed to obtain bran as described below, which is a typical processing technique for sorghum grain utilization in Nigeria.

Figure 1 shows a schematic diagram of a proposed sorghum based biorefining process. The sorghum bran is steeped and milled to separate the sorghum bran from starch. Starch is the main product while the waste sorghum bran is hydrolyzed by either enzyme or acid to generate a sugar-rich hydrolysate. The hydrolysate is then fermented to produce bioethanol via yeast fermentation. Waste yeast together with un-fermented solid residue can be used as high protein animal feed.

\subsection{Bran preparation}

The sorghum grains were washed twice with distilled water and steeped for two days at room temperature with a water to biomass ratio of $4: 1(\mathrm{v} / \mathrm{v})$. They were washed again, then wet-milled in a conventional petrol-powered wet-mill until a smooth slurry was obtained. The slurry was sieved through muslin cloth to remove the starchy endosperm material. The bran residue was then air dried until a brittle, lumpy bran was obtained. These brans were comminuted in a planetary Ball Mill (Fritsch, Gmbh) to obtain a freeflowing powder. Twelve ceramic balls were added to each of two zirconium oxide pots and then filled with bran to about $75 \%$ capacity. The pots were closed and spun at 250 rpm for three cycles of 3 mins and two pauses of 2 mins (to prevent over-heating). The milled sorghum bran was stored in cool dry conditions pending use.

\subsection{Sorghum bran compositional analysis}

Total ash was determined according to the method of Sluiter et al. [32]. The total carbohydrates were determined by a two-step concentrated acid hydrolysis of the sorghum bran [33]. The reducing sugar component was determined by using the DNS method [34]. The starch content was determined using an enzymatic starch analysis kit (Megazyme®, Ireland). Structural carbohydrates were determined after the deduction of the starch's contribution to the carbohydrate content thus:

Starch glucan x $1.1=$ glucose content attributable to starch

(Eqn. 1)

Glucose content attributable to cellulose $=$ Total glucose estimated - glucose content attributable to starch

(Eqn. 2)

Cellulose $=($ Glucose attributable to cellulose + mannose $) \times 0.9$

(Eqn. 3)

Hemicellulose $=($ Xylose + arabinose $) \times 0.88$

(Eqn. 4)

where 1.1, 0.9 and 0.88 represent the conversion factors for starch, cellulose and hemicellulose respectively.

Lignin content was determined by the amended acetyl bromide method [35]. Protein content was determined using the Thermo Scientific FlashEA 1112 N/Protein Analyser (Thermo Fisher Scientific, UK), which estimates protein based on a complete combustion of the sample in a furnace, and then analyses the elemental gases produced.

Total lipid content was determined by gas chromatography (GC) via the direct fatty acid synthesis method. Briefly, $1.0 \mathrm{~g}$ of ball milled bran samples, $0.7 \mathrm{~mL}$ of $10 \mathrm{M} \mathrm{KOH}$ and $5.3 \mathrm{~mL}$ of methanol were added into a test tube. The tubes were incubated at $55^{\circ} \mathrm{C}$ and vortexed at $20 \mathrm{~min}$ intervals for $90 \mathrm{~min}$, before being transferred to an ice-water bath for $10 \mathrm{~min}$ to cool. Next, $0.58 \mathrm{~mL}$ of $12 \mathrm{M} \mathrm{H}_{2} \mathrm{SO}_{4}$ was added to the samples, vortexed and the incubation and cooling steps repeated once. Then, $3 \mathrm{~mL}$ of hexane was added to the samples and each tube vortexed for $30 \mathrm{sec}$ then spun in a centrifuge (Eppendorf, U.K.) at 1,500 rpm for $5 \mathrm{~min}$. The top fatty acid-hexane layer was then transferred to labelled LP4 tubes and dried by blowing nitrogen through them. The residual fatty acids were re- 
suspended in $300 \mu \mathrm{L}$ hexane, vortexed and transferred to solvent-resistant Eppendorf tubes from which $100 \mu \mathrm{L}$ was transferred into vials with inserts and analysed by gas chromatography.

All solutions were prepared using reverse-osmosis (RO) water and all chemicals used were analytical grade purchased from either Fisher Scientific or Sigma-Aldrich. All analyses were performed in triplicate, and results are presented as mean values \pm standard deviations

\subsection{Sorghum Bran Hydrolyses}

Two hydrolyses methods were investigated for hydrolysate production from both white and red sorghum brans.

\subsubsection{Enzymatic hydrolysis}

Enzymatic hydrolysis was carried out following the starch analysis method recommended by Megazyme $\AA$, Ireland with minor modifications. Briefly, a slurry of $200 \mathrm{~g}$ bran and $700 \mathrm{~mL}$ of water was prepared in duplicate in $1 \mathrm{~L}$ Duran bottles, followed by the addition of $100 \mathrm{~mL}$ dimethyl sulfoxide (DMSO). The mixture was mixed, then incubated in a shaking water bath at $95^{\circ} \mathrm{C}, 140 \mathrm{rpm}$ for $15 \mathrm{~min}$ to gelatinize it. Next porcine pancreatic amylase (250 U/g sorghum bran, Sigma-Aldrich) in 0.2 M sodium acetate buffer ( $\mathrm{pH}$ 6.9) was added and the slurry incubated for further $10 \mathrm{~min}$. It was then cooled to $50^{\circ} \mathrm{C}$. Then $250 \mathrm{U} / \mathrm{g}$ amyloglucosidase from Aspergillus niger (Sigma-Aldrich, UK) in $0.2 \mathrm{M}$ sodium acetate buffer ( $\mathrm{pH} 4.5$ ) was added. The reaction was left to proceed for 40 min then the volume was adjusted to $1 \mathrm{~L}$ and reacted for a further $24 \mathrm{hr}$. Samples were collected at regular intervals, and the sugar content was analysed by HPLC.

Glucose yield $=\frac{\text { Glucose content }}{\text { Weight of bran } \times \text { starch content } \times 1.11}$

(Eqn. 5)

\subsubsection{Dilute acid hydrolysis}

The dilute acid hydrolysis was carried out using either sulphuric acid or nitric acid at $1 \%$ or $3 \%(\mathrm{w} / \mathrm{w})$ as follows. Exactly $500 \mathrm{mg}$ of white bran (WB) or red bran (RB) was made up to a volume of $10 \mathrm{~mL}$ with the acids and vortexed, then autoclaved at $121^{\circ} \mathrm{C}$ for 15 or 30 min, respectively. The cooled slurry was vacuum-filtered through Whatman No. 1 filter paper and the sugar content was analysed by high performance liquid chromatography (HPLC).

Using the best conditions obtained from the experiment above, the effect of loading ratio on efficiency of sugar release was further investigated. Loading ratios of 5\%, 10\% and $20 \%$ bran (w/v) in dilute acid respectively were studied. The optimum conditions obtained were then combined for the preparation of large volumes of hydrolysates for fermentation.

All hydrolysates were stored at $4^{\circ} \mathrm{C}$ pending use, and filter sterilized using $0.2 \mu \mathrm{m}$ Stericup ${ }^{\circledR}$ filters (Millipore, USA) before fermentation.

\subsection{Microorganisms}

Eight yeast strains with reported ethanologenic abilities [36][37] [38] were investigated in this study for the conversion of sorghum bran hydrolysate to bioethanol (Table 1). 


\subsection{Inoculum preparation}

Frozen stock cultures of the yeasts were revived by streaking on YPD agar plates $(10 \mathrm{~g} / \mathrm{L}$ yeast extract, $20 \mathrm{~g} / \mathrm{L}$ peptone, $20 \mathrm{~g} / \mathrm{L}$ glucose and $15 \mathrm{~g} / \mathrm{L}$ agar) and incubated at $30^{\circ} \mathrm{C}$ for $48 \mathrm{hr}$. Representative colonies were then used to inoculate $10 \mathrm{~mL}$ of YPD broth $(10 \mathrm{~g} / \mathrm{L}$ yeast extract, $20 \mathrm{~g} / \mathrm{L}$ peptone, $20 \mathrm{~g} / \mathrm{L}$ glucose) and incubated at $30^{\circ} \mathrm{C}, 150 \mathrm{rpm}$ for $48 \mathrm{hr}$. The cells were harvested by centrifugation at $17,000 \times \mathbf{g}$ for $5 \mathrm{~min}$ and the supernatant discarded, the pellets washed with sterile reverse osmosis water and centrifuged at 17,000 $\mathrm{x}$ g. Cells were washed three times to remove any traces of the medium before being resuspended in $5 \mathrm{~mL}$ of sterile distilled water for use as inocula [36].

\subsection{Yeast screening tests}

Spot plate screening was performed according to the method of Greetham et al. [36] with the modification that in this work, sorghum bran hydrolysate replaced YNB and glucose in the original medium. A cell suspension with $\mathrm{OD}_{600}$ of 1.0 was serially diluted by tenfold stages and a $5 \mu \mathrm{L}$ aliquot of each strain was aseptically transferred on to a plate of sorghum bran agar. Four plates of each hydrolysate were prepared. The plates were left undisturbed until the spots were completely dry, two plates of each hydrolysate were then incubated aerobically or anaerobically at $30^{\circ} \mathrm{C}$, for $72 \mathrm{hr}$. Anaerobic conditions were generated by placing each plate in a PM gas bag (Biolog, USA) which were then vacuum packed in an Audion VMS43 vacuum chamber (Audion Elektro BV, Netherlands). The plates were then photographed using a Bio-Rad-transilluminator (Bio-Rad, Cambridge, UK).

For phenotypic microarray (PM) analysis, the transmittance of the cell suspension was measured using a Biolog turbidimeter (Biolog, USA) and adjusted to 62\% (approximately $5 \times 10^{6}$ cells $/ \mathrm{mL}$ ) with sterile RO water. For spot plate assay, suspensions were serially diluted in sterile RO water in cuvettes. They were covered with Nescofilm (Fisher Scientific, UK), inverted severally to mix and their absorbances were read at $600 \mathrm{~nm}$ with sterile RO water as the blank. The cell concentrations were adjusted with sterile RO water to an $\mathrm{OD}_{600}$ of 1.0 on a spectrophotometer (Bibby Scientific Ltd., UK) [36]. Next, $0.2 \mu \mathrm{L}$ of a tetrazolium dye was measured into each well of a bespoke 96-well plate. Exactly 30 $\mu \mathrm{L}$ of the white bran enzyme hydrolysate (WBEH) was transferred into the first three wells. This was followed, also in triplicates, by the red bran enzyme hydrolysate (RBEH), white bran dilute acid hydrolysate (WBDAH) and red bran dilute acid hydrolysate (RBDAH) respectively in the succeeding wells. This was repeated for four more rows in the same arrangement, thus preparing 5 rows for the test organisms. Next, $125 \mu \mathrm{L}$ of the yeast cell suspension were mixed with $2.65 \mathrm{~mL}$ of IFY ${ }^{\mathrm{TM}}$ buffer (Biolog, USA) and adjusted to a final volume of $3 \mathrm{~mL}$ with sterile RO water followed by the addition of 90 $\mu \mathrm{L}$ of the cell suspension to each well. Each row of 12 wells was thus inoculated with just one organism. A final 15 wells were filled with YPD medium as controls for the hydrolysates and inoculated with the yeasts in triplicates in the same order [36].

\subsection{Mini-fermentations}

Four hydrolysates: WBEH, RBEH, WBDAH and RBDAH were fermented with the bestperforming strains from the screening. Anaerobic fermentations were performed in 25 $\mathrm{mL}$ of sterile hydrolysate at $\mathrm{pH} 5.0$ in Wheaton glass bottles $(30 \mathrm{~mL}$; Wheaton, USA) based on a method adapted from Powell et al. [39]. Cells were pitched at 1 x $10^{7}$ cells $/ \mathrm{mL}$, the bottles were capped, and the set-up weighed to the nearest $0.1 \mathrm{mg}$. They 
were then placed on magnetic stirrer plates set at $120 \mathrm{rpm}$ and placed in an incubator (MIR-253, Sanyo Electric Co., Japan) set at $30^{\circ} \mathrm{C}$. Weight loss resulting from carbon dioxide release through the Bunsen valves in the cap was monitored periodically. The fermentation proceeded until constant weight was observed over several time points. For time-point experiments, triplicate samples were terminated at different times and analysed while other replicates were allowed to proceed.

Ethanol yields were expressed as a function $(\mathrm{g} / \mathrm{g})$ of the maximum possible based on the glucose consumed, and then this amount was expressed as a proportion (\%) of the theoretical maximum yield of ethanol $(0.51 \mathrm{~g} / \mathrm{g})$ as shown in Equation 6.

Yield (\%) of theoretical maximum $=\left(\frac{\text { Actual Yield }}{0.51}\right) \times 100$

(Eqn. 6)

\subsection{Sugar and inhibitor content analysis by HPLC}

The sugar contents of sorghum hydrolysates, residual sugar and ethanol yields in fermentation broths were determined by HPLC. The samples were centrifuged to remove solids, appropriately diluted then syringe-filtered $\left(0.2 \mu \mathrm{m}\right.$ Minisart $\left.{ }^{\circledR}\right)$ into HPLC vials. The modular HPLC setup comprised an AS-2055 auto-sampler, PU-1580 pump and RI2031 refractive index detector (Jasco International Co. Essex, UK). Sample injection volume was $10 \mu \mathrm{L}$ and separation was achieved using a Hi-Plex $\mathrm{H}^{+}$column $(7.7 \mathrm{~mm} \mathrm{x}$ 300mm; Agilent Technologies, Inc., USA) at $45^{\circ} \mathrm{C}$ in a Series II $5890 \mathrm{GC}$ oven (Hewlett Packard, CA, USA). The mobile phase was $0.005 \mathrm{~N} \mathrm{H}_{2} \mathrm{SO}_{4}$ solution at a flow rate of 0.4 $\mathrm{mL} / \mathrm{min}$.

The presence of common inhibitors of ethanol fermentation was also investigated in the hydrolysates. The HPLC system (Waters Limited, UK) was fitted with a Techsphere ODS-2 column, photodiode array detector, pump and computer system. An injection volume of $10 \mu \mathrm{L}$ of the samples was then run by a gradient method using a mixture of neat methanol and a 1:1 methanol:water mixture at a flow rate of $0.5 \mathrm{~mL} / \mathrm{min}$. Standard solutions containing $0.125-1 \mathrm{~g} / \mathrm{L}$ of syringaldehyde, acetic acid, 5-hydroxymethylfurfural (5-HMF), furaldehyde, ferulic acid and vanillic acid were prepared in RO water and analysed by HPLC.

All analyses were performed in triplicate, and results are presented as mean values \pm standard deviations

\subsection{Statistical analyses}

Student's T-test was performed to determine the significance of different experimental groups, while $\mathrm{p}<0.05$ was considered as significant difference.

\subsection{Estimation of bioethanol production potential}

The bioethanol production potential (Bioethanol $s$, g bioethanol per $\mathrm{g}$ sorghum bran) from sorghum bran was estimated using Equation 7:

Bioethanol $_{S B}=$ Equivalent sugar content $_{S B} \times Y_{H} \times Y_{F} \times 0.511 \quad$ (Eqn. 7) where, Equivalent sugar content $S B$ is the equivalent glucose component in sorghum bran $(\mathrm{g} / \mathrm{g}) ; Y_{H}$ is the yield of hydrolysis $(\mathrm{g} / \mathrm{g}) ; Y_{F}$ is the fermentation yield (\% of theoretical yield, $\mathrm{g} / \mathrm{g}), 0.511$ is the theoretical bioethanol mass yield using glucose as the substrate.

The annual bioethanol production potential was estimated using Equation 8: 


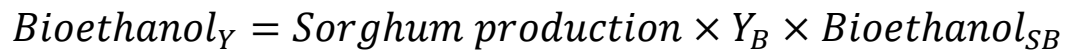

(Eqn. 8)

where, $Y_{B}$ is the yield of sorghum bran content obtained from sorghum milling process $(\mathrm{g} / \mathrm{g})$.

\section{Results and Discussion}

In this study, sorghum bran, an underutilised biomass in Nigeria was investigated for its potential use in the biosynthesis of value-added products, using the production of bioethanol as an example. The sorghum milling waste was found to have a favourable carbohydrate and other nutrient content, meaning that hydrolysates from the sorghum bran could be used successfully by certain yeasts to produce promising levels of bioethanol as described below.

\subsection{Sorghum Bran Composition}

The composition of the sorghum bran is presented in Table 2. The air-dried white bran (WB) had a moisture content (MC) of $11.6 \%$, so it was further oven-dried at $37^{\circ} \mathrm{C}$ to a $\mathrm{MC}$ of $6.8 \%$ to prevent spoilage during storage and to prevent interference by excess moisture with acid concentrations [33]. The sorghum bran was found to have a relatively high starch content of 49.7-53.0\%, which contrasted with a lower value of $30 \%$ reported by Corredor et al. [22]. This could be due to the bran layer in the sorghum grain kernel being not as brittle as that found in wheat [40], which is easily separated from starch granules during milling processing. The high starch content in sorghum bran makes the bran an ideal potential substrate for bioconversions. Similar high starch contents of 50$60 \%$ have been reported for cassava bagasse by Sriroth et al. [41] and Pandey et al. [42], and a starch content of $52.3 \%$ for oats bran by Bhatty [43]. The lignocellulosic material contents were around $20 \%$ in total. Lignocellulose is the main structural material found in the sorghum pericarp, testa and aleurone tissues [44] and these were retained in the bran. A high protein content (15.6-16.9\%) was detected for both WB and red bran (RB), indicating that they are nutritionally balanced substrates with the potential to be used in bioethanol production.

\subsection{Sorghum Bran Hydrolysis}

\subsubsection{Enzymatic Hydrolysis}

Glucose was produced relatively quickly during the enzymatic hydrolysis of the brans, but the accumulation of glucose stopped after $4 \mathrm{hr}$ (Figure 2). The glucose concentrations in the hydrolysate were $55 \mathrm{~g} / \mathrm{L}$ and $61 \mathrm{~g} / \mathrm{L}$ for $\mathrm{WB}$ and $\mathrm{RB}$ respectively, corresponding to a hydrolysis yield of $49.9 \%$ and $57.6 \%$, respectively. The higher glucose content in RB correlated with RB having a higher starch content than WB. The yields were lower than the $75 \%$ reported by Corredor et al. [22] from sorghum bran where a combined hot water treatment $\left(132^{\circ} \mathrm{C}\right.$ for $\left.20 \mathrm{~min}\right)$ and enzymatic hydrolysis was utilised. By contrast, only a 9\% yield was achieved using enzymatic hydrolysis without hot water treatment, [22], indicating the importance of sufficient gelatinization of the substrate material. The relatively low enzymatic hydrolysis yield in this study might therefore be attributed to insufficient gelatinization at $95^{\circ} \mathrm{C}$ for $15 \mathrm{~min}$. 


\subsubsection{Dilute Acid Hydrolysis}

In addition to enzymatic hydrolysis, dilute acid hydrolysis of sorghum bran was tested as a potentially cost effective route and less complex technology for wider acceptability in developing countries. To determine suitable hydrolysis conditions, the effects of dilute sulphuric (at $1 \%$ and $3 \%$ concentrations) and nitric (at $1 \%$ concentration) acid treatment for 15- and 30-min reaction times were compared (Table 3).

Glucose was found to be the main monosaccharide in the hydrolysate, with no significant difference in glucose release by the different acids $(p>0.05)$. The concentration of sulphuric acid used in WB hydrolysis had a significant effect on glucose release, with 3\% acid releasing more sugar $(\mathrm{p}=0.0009)$, with increased treatment time also leading to greater yield of glucose $(\mathrm{p}=0.0358)$. For $\mathrm{RB}$, increased sulphuric acid concentration also led to a significantly increased glucose yield $(p=0.0202)$, whereas the impact of residence time was here not significant $(\mathrm{p}=0.2957)$. The highest glucose concentration achieved $(34.53 \pm 8.04 \mathrm{~g} / \mathrm{L})$ was with WB treated with $3 \%$ sulphuric acid for $30 \mathrm{~min}$ (Table 3). Residence time was also found to be not of great significance in the hydrolysis of microalgae (Chlamydomonas reinhardtii) [45]. It was discovered that the marginal increase in sugar recovered was not worth the economic implication of increasing the residence time above $30 \mathrm{~min}$. Similar results were also reported in the hydrolysis of moso bamboo residues $[12,46]$.

To further the dilute acid hydrolysis investigation, the impact of Solid Loading Ratio (SLR) was investigated as it was reported to be an important factor to determine the concentrations of released sugars [47, 48]. Figure 3 shows the main sugar concentrations obtained at different SLR. It was observed that glucose concentrations increased from $35.4 \mathrm{~g} / \mathrm{L}$ at $5 \%$ SLR to $41.2 \mathrm{~g} / \mathrm{L}$ and $46.9 \mathrm{~g} / \mathrm{L}$ at $10 \%$ and $20 \%$ SLR of $\mathrm{WB}$, respectively. Similarly, 21.8, 41.6 and $52.1 \mathrm{~g} / \mathrm{L}$ glucose was obtained at 5\%, $10 \%$ and $20 \%$ SLR respectively for the RB. Statistical analyses revealed that these increases were significant in RB but not significant in WB.

By contrast, the relative sugar hydrolysis yields decreased with increasing SLR (Figure 3). For instance, the efficiency for WB was $112.5 \%$ at 5\% SLR, $65.5 \%$ at $10 \%$ SLR, and $37.3 \%$ at $20 \%$ SLR. The reason that over $100 \%$ hydrolysis yield was observed was mainly due to the fact that a different batch of WB was used in the hydrolysis experiment to that used in the sorghum bran composition analysis (Table 2). The starch and cellulose composition varied slightly from batches to batches. A similar trend of hydrolysis yield decreasing along with increasing SLR was observed with RB. This phenomenon could be due to non-uniform contact of acids with the solids which sediment when present in high concentration. Recalcitrant oligomers may be formed due to the incomplete digestion of the carbohydrate polymers at high SLR [49], leading to a low hydrolysis yield. It is evident that the marginal increase in sugars released from $10 \%$ to $20 \%$ SLR does not justify the considerable waste in form of undigested bran due to decreased efficiency at the $20 \%$ SLR. In addition, since the highest increase in sugar release was observed moving from $5 \%$ to $10 \%$ SLR, the $10 \%$ level was selected for the subsequent production of sorghum bran hydrolysates. This figure is similar to the $13.1 \%$ SLR recommended for dilute acid hydrolysis of agave bagasse [50].

The overall yields from the dilute acid hydrolysis treatments were comparable with those from enzyme hydrolysis (Figure 1). This was an important finding given that sulphuric acid is a relatively cheap albeit strong acid [51], available at less cost than commercial enzymes. The dilute acid hydrolysis process is also arguably a more accessible process requiring less expertise. 


\subsubsection{Inhibitor Profile in the Hydrolysate}

The presence of known inhibitory compounds of ethanol fermentation in the various sorghum bran hydrolysates was determined. The enzyme hydrolysates contained significantly lower levels of all of the inhibitor compounds than the dilute acid hydrolysates, except for acetic acid where levels were similar (Table 4). However, the inhibitory compounds were in general at considerably lower concentrations $(\mathrm{mg} / \mathrm{L})$ than reported previously for many lignocellulosic hydrolysates. For example, steam explosion of poplar led to the release of $2.1 \mathrm{~g} / \mathrm{L}$ of acetic acid, $490 \mathrm{mg} / \mathrm{L}$ of furfural, $50 \mathrm{mg} / \mathrm{L}$ of syringaldehyde and $14 \mathrm{mg} / \mathrm{L}$ of vanillin [52]. The maximal 5-HMF concentration observed in this work was $5.9 \mathrm{mg} / \mathrm{L}$, which was less than $0.15 \mathrm{~g} / \mathrm{L}$ reported for the hydrolysis of potato starch using $2 \mathrm{M} \mathrm{HCl}$ at $98^{\circ} \mathrm{C}$ [53], and is significantly less than the maximum 5-HMF concentration $(0.2 \%)$ that the yeast Saccharomyces cerevisiae can tolerate [54].

\subsection{Selection of Yeast Strains}

Six yeast species and eight strains in total were employed in this study. These were selected based on favourable physiological characteristics including: (i) high potential ethanol yields (e.g. Saccharomyces spp.); (ii) the ability to ferment pentose sugars (e.g. Candida aravinofermentans, Scheffersomyces stipitis); and (iii) high tolerance to fermentation inhibitors [37]. Strain screening tests were performed to determine the best strain(s) to utilize the sorghum bran hydrolysates.

The spot plate test showed that all the yeasts successfully metabolized and grew on the sorghum bran hydrolysate under both aerobic and anaerobic conditions (Figure 4). Colonies on the dilute acid hydrolysates (DAH) were smaller than those on their enzyme hydrolysate $(\mathrm{EH})$ equivalents. This was likely due to differences in the glucose content, which was about $33.6 \mathrm{~g} / \mathrm{L}$ in the DAH batch used as compared to about $54 \mathrm{~g} / \mathrm{L}$ in the EH and/or relatively higher inhibitor contents in DAHs.

The aerobic plates exhibited more typical yeast colonial growth, whereas the colonies on the anaerobically incubated EH plates showed a mat-forming, spreading tendency at every dilution. Yeast species show remarkably complex, strain-specific morphologies that are influenced by the environmental conditions including showing different morphologies under different conditions in the same media, and in different media under the same conditions [41]. It is likely that the absence of oxygen in the anaerobically incubated plates (Figures 4A and C) triggered the changes in growth phenotype in a similar way.

Phenotypic microarray (PM) analysis of the yeast strains, when grown on the various sorghum bran hydrolysates, was carried out which monitors respiration activity in a 96well plate (Figure 5) [36,56]. S. stipitis showed the least metabolic activity while $C$. arabinofermentans and S. cerevisiae 1119 showed the highest activity (Figure 5). All strains showed typical respiration profiles except for $W$. anomalous, which had a relatively sharp decline in redox signal intensity at $10 \mathrm{hr}$ in all the media, before plateauing into the log phase (Figure 5). The variation in the redox signal intensity (RSI) was considerable, ranging from 65.7 for S. stipitis to 116 for S. pastorianus at $70 \mathrm{~h}$ on RBEH and 58.7 (for S. stipitis) and to 106.7 (S. cerevisiae 1119), on WBEH. A similar trend was observed with the DAHs where the pattern of the growth signal was almost exactly the same for all species on both bran hydrolysates. The poor growth of S. stipitis was attributed to its sensitivity to inhibitors, and high oxygen demand [36]. Low RSI of 
S. stipitis in PM analysis using glucose as a sole carbon source has also been reported on wheat straw and macroalgae hydrolysates [57].

Generally, the RSIs on EHs were about double that of DAHs, which was directly correlated with the concentration of sugars. The similarity in the metabolic profiles of strains on both bran types indicated that both bran types and both hydrolysate method could adequately support the growth of the yeasts that were tested.

\subsection{Bioethanol Fermentation}

Based on the strain selection experiment, S. pastorianus and $K$. marxianus were selected for models to assess possible bioethanol production when using sorghum bran hydrolysate as the fermentation substrate. Strain S. cerevisiae NCYC 2592 was also included as a reference control strain. In the fermentations a steady decline in weights of the growth vessels was observed, which correlated with sugar catabolism into $\mathrm{CO}_{2}$ [39]. This indicates that sorghum bran hydrolysate contained sufficient nutrients for a microbial fermentation. Although PM assay showed a similar response for both brans, $\mathrm{RB}$ showed a greater weight loss (Figures 6B and D) which correlated with higher ethanol production (Table 5). The EHs had higher glucose contents than the DAHs, which explained the higher weight loss observed in the former due to the greater bioethanol formation and $\mathrm{CO}_{2}$ release. $\mathrm{RBEH}$ showed the highest weight loss, losing $2.2 \%$ of the vessel weight (using S. cerevisiae NCYC 2592) compared to WBEH with $1.4 \%$. This was higher than previous reports of the highest weight loss of $0.25-0.35 \%$ by yeasts on the hydrolysates of two macroalgae Chondrus crispus and Palmaria palmata [57].

There were differences in the progression of fermentation among the three strains although the overall trends were similar. The weight loss shown by S. cerevisiae NCYC 2592 in all media was almost complete after $48 \mathrm{hr}$ whereupon the culture entered the stationary phase. S. pastorianus had the longest lag phase and least weight loss (Figure 6). S. cerevisiae NCYC 2592 also showed the highest weight loss in all media except RBDAH, in which $K$. marxianus showed maximum weight loss.

The highest bioethanol titre of $24.35 \mathrm{~g} / \mathrm{L}$ was produced by $K$. marxianus in RBEH (Table 5). This shows a direct correlation between metabolic activity as indicated by the weight loss and ethanol production. K. marxianus is a thermotolerant yeast which has been reported to be a good alternative to $S$. cerevisiae in bioethanol production [58] and produced over $90 \mathrm{~g} / \mathrm{L}$ ethanol from a mixture of whey and molasses [59]. This study also confirmed that both types of sorghum bran hydrolysates provide a suitable growth substrate for $K$. marxianus.

There was no significant difference between the ethanol concentrations obtained with the white or red bran enzyme hydrolysates and between three yeasts. However, with the dilute acid hydrolysates, all strains produced significantly higher ethanol concentrations with RBDAH than WBDAH. Higher bioethanol concentrations and higher yields were obtained when using the enzyme hydrolysates than the dilute acid hydrolysates for all strains (Table 5). This is likely due to their relatively lower inhibitors content of the enzyme hydrolysates (Table 4). The highest ethanol yield of $89 \%$ of the theoretical maximum was obtained from RBEH, which was higher than the $78 \%$ reported yield obtained in fermentation of bagasse [14] and was comparable with the $91 \%$ yield reported by Erdei et al. from the fermentation of pre-saccharified wheat meal [60]. Statistical analysis showed no significant differences $(p=0.6825)$ in the performance of the three strains. 


\subsection{Estimation of bioethanol production potential}

To calculate the bioethanol production yield from sorghum bran, the generic feedstock obtained from the dilute acid hydrolysis of red sorghum bran was used. The hydrolysis yield $Y_{H}$ was 0.644 at a SLR of $10 \%$ and the fermentation yield $Y_{F}$ was $70.9 \%$. Based on Equation 7, the bioethanol yield achieved in this study was $0.151 \mathrm{~g}$ bioethanol per $\mathrm{g}$ sorghum bran. In 2016, sorghum production in Nigeria was 7.56 million tonnes [61]. The sorghum bran content $Y_{B}$ was $64 \%$ (w/w, unpublished data) obtained from a traditional sorghum milling process that was commonly used in Nigeria. Therefore, there is a potential annual bioethanol production of $0.73 \mathrm{~m}$ ton ( 244 million US gallon) per year. Figure 7A shows a schematic diagram of the mass balance for the bioethanol production estimation.

For the estimation of bioethanol production potential from sorghum bran, the cellulose and hemicellulose content was considered for the calculation of equivalent sugar content, which was $70.2 \%$ (w/w, glucose equivalent). With an improvement of hydrolysis and fermentation efficiency, the hydrolysis yield and fermentation yield were estimated to be 90\% $\left(Y_{H}\right)$ and $95 \%\left(Y_{F}\right)$, respectively, the same as the targets set by NREL (National Renewable Energy Laboratory, USA) [62]. Based on this estimation, a bioethanol yield $0.307 \mathrm{~g}$ bioethanol per $\mathrm{g}$ sorghum bran could be achieved. The annual bioethanol production using all the sorghum bran available in Nigeria could therefore reach $1.48 \mathrm{~m}$ ton (497 million US gallon, 44.5 million GJ) annually (Figure 7B). It was estimated that the transportation fuel usage in Nigeria was 6.15 million ton (crude oil equivilant, 258 million GJ) in 2007 [63], the bioethanol production from sorghum bran could potentially provide $17 \%$ of transportation fuel in Nigeria (based on energy content). This would significantly contribute to the biofuel industry in Nigeria.

\section{Conclusion}

Sorghum bran is an under-utilized waste stream from the sorghum milling process in Nigeria which contains relatively high amounts of starch and proteins, indicating that it is a suitable substrate for fermentative conversion to value added products. Enzymatic hydrolysis of sorghum bran resulted in hydrolysates containing 55-61 g/L glucose, with a yield of around $50-58 \%$. Dilute acid hydrolysis led to a relatively low sugar concentration of 26-35 g/L. The hydrolysates supported the growth and metabolism of different yeast genera, and ethanol production at high yields of $63-89 \%$ of the theoretical maximum. With a bioethanol production yield of $0.151 \mathrm{~g}$ bioethanol per $\mathrm{g}$ sorghum bran, it is estimated that if all the sorghum bran produced in Nigeria were utilized, the bioethanol produced could provide 17\% of Nigeria's annual transportation fuel requirements. Thus, this work shows that fermentative bioethanol can be produced using low-cost sorghum bran hydrolysates, and it could potentially contribute significantly to the biofuel industry in Nigeria.

\section{Acknowledgements}

The authors gratefully acknowledge the financial support of the Tertiary Education Fund (TETFund) of the Federal Government of Nigeria for a $\mathrm{PhD}$ scholarship granted to Amina Ahmed El-Imam. Dr. Darren Greetham also gratefully acknowledges funding from the University of Huddersfield, under the URF programme (URF2015/24). 


\section{References}

[1] A.K.J. Donald J. Wuebbles, Concerns about climate change and the role of fossil fuel use, Fuel Process. Technol. 71 (2001) 99-119.

[2] J. Hill, E. Nelson, D. Tilman, S. Polasky, D. Tiffany, Environmental, economic, and energetic costs and benefits of biodiesel and ethanol biofuels, Natl. Acad Sci. 103 (2006) 11206-11210.

[3] J. Milano, H. Ong, H. Masjuki, W. Chong, M.K. Lam, P.K. Loh, V. Vellayan, Microalgae biofuels as an alternative to fossil fuel for power generation, Renew. Sustain. Energy Rev. 58 (2016) 180-197.

[4] J.K. Saini, R. Saini, L. Tewari, Lignocellulosic agriculture wastes as biomass feedstocks for second-generation bioethanol production: concepts and recent developments, Biotech. 5 (2015) 337-353. doi:10.1007/s13205-014-0246-5.

[5] A. Avci, B. Saha, B. Dien, G. Kennedy, MA Cotta, Response surface optimization of corn stover pretreatment using dilute phosphoric acid for enzymatic hydrolysis and ethanol production, Bioresour. Technol. 130 (2013) 603-612.

[6] C. Ibeto, A. Ofoefule, K. Agbo, A global overview of biomass potentials for bioethanol production: a renewable alternative fuel, Trends Appl Sci. (2011).

[7] K. Sriroth, S. Wanlapatit, K. Piyachomkwan, Cassava bioethanol, InTechOpen, 2012. http://cdn.intechopen.com/pdfs/27348/InTech-Cassava_bioethanol.pdf (Accessed 05 Aug, 2019)

[8] P. Gerbens-Leenes, Bioenergy water footprints, comparing first, second and third generation feedstocks for bioenergy supply in 2040, Eur. Water. 59 (2017) 373380.

[9] B. Hahn-Hägerdal, M. Galbe, M.F. Gorwa-Grauslund, G. Lidén, G. Zacchi, Bioethanol - the fuel of tomorrow from the residues of today, Trends Biotechnol. 24 (2006) 549-556. doi:10.1016/J.TIBTECH.2006.10.004.

[10] S. Mohapatra, C. Mishra, S. Behera, H. Thatoi, Application of pretreatment, fermentation and molecular techniques for enhancing bioethanol production from grass biomass-a review, Renew. Sustain. Energy Rev. 78 (2017) 1007-1032.

[11] J. Rahikainen, S. Mikander, K. Marjamaa, T. Tamminen, A. Lappas, L. Viikari, K. Kruus, Inhibition of enzymatic hydrolysis by residual lignins from softwoodstudy of enzyme binding and inactivation on lignin-rich surface, Biotechnol. Bioeng. 108 (2011) 2823-2834.

[12] C. Huang, Q. Chu, Y. Xie, X. Li, Y. Jin, D. Min, Effect of kraft pulping pretreatment on the chemical composition, enzymatic digestibility, and sugar release of moso bamboo residues, Bioresources. 10 (2015) 240-255.

[13] C. Huang, J. Ma, C. Liang, X. Li, Q. Yong, Influence of sulfur dioxide-ethanolwater pretreatment on the physicochemical properties and enzymatic digestibility of bamboo residues, Bioresour. Technol. 263 (2018) 17-24.

[14] M. Irfan, M. Nadeem, Q Syed, Ethanol production from agricultural wastes using Saccharomyces cerevisae, Brazilian J. Microbiol. 45 (2014) 457-465.

[15] P. Rogers, K. Lee, D. Tribe, High productivity ethanol fermentations with Zymomonas mobilis, Process Biochem. 15 (1980) 7-11.

[16] C. Tuck, E. Pérez, I. Horváth, R. Sheldon, Valorization of biomass: deriving more value from waste, Science (80-. ). 337 (2012) 695-699.

[17] B. Saha, Production of mannitol by fermentation, in: Ferment. Biotechnol., American Chemical Society, 2003: pp. 67-85.

[18] J. Agger, K.S. Johansen, A.S. Meyer, PH catalyzed pretreatment of corn bran for 
enhanced enzymatic arabinoxylan degradation, N. Biotechnol. 28 (2011) 125-135. doi:10.1016/j.nbt.2010.09.012.

[19] J.E. Lee, P. V. Vadlani, J. Faubion, Corn bran bioprocessing: Development of an integrated process for microbial lipids production, Bioresour. Technol. 243 (2017) 196-203. doi:10.1016/j.biortech.2017.06.065.

[20] H. Macauley, Cereal crops: Rice, maize, millet, sorghum, wheat, in: T. Ramadjita (Ed.), Feed. Africa An Action Plan African Agric. Transform., Africa Development Bank, Dakar, 2015: p. i.

[21] D.Y. Corredor, S.R. Bean, T. Schober, D. Wang, Effect of decorticating sorghum on ethanol production and composition of DDGS, Cereal Chem. J. 83 (2006) 1721. doi:10.1094/CC-83-0017.

[22] D.Y. Corredor, S. Bean, D. Wang, Pretreatment and enzymatic hydrolysis of sorghum bran, Cereal Chem. J. 84 (2007) 61-66. doi:10.1094/CCHEM-84-1-0061.

[23] C. Lyddon, Focus on Nigeria, Worldgrain.Com. (2019) 1. http://www.worldgrain.com/articles/11643-focus-on-nigeria.

[24] Anonymous, Nigeria to set up $\$ 50$ billion biofuel equity fund, Financ. Niger. (2018) 1.

[25] A. Eisentraut, A. Brown, L. Fulton, Technology roadmap: biofuels for transport, Parix Cedex Int. Energy Agency. (2011).

[26] E.A. Abu, Enzymatic saccharification of some agro-industrial cellulosic wastes by cellulose produced from a mixed culture of Aspergillus Niger and Saccharomyces cerevisae, Ife J. Sci. 6 (2004) 84-87.

[27] E. Abu, S. Ado, D. James, Raw starch degrading amylase production by mixed culture of Aspergillus niger and Saccharomyces cerevisae grown on sorghum pomace, African J. Biotechnol. 4 (2005) 785-790.

[28] J. Abdullah, A. Ahmed El-Imam, D. Greetham, C. Du, Tucker, The application of fungi for bioleaching of municipal solid wastes for the production of environmental acceptable compost production, J. Environ. Sci. Public Heal. 1 (2017) 167-194.

[29] N. Dunford, Food and industrial bioproducts and bioprocessing, John Wiley \& Sons. 2012.

[30] R. Zhao, S. Bean, X. Wu, D. Wang, Assessing fermentation quality of grain sorghum for fuel ethanol production using rapid visco-analyzer, Cereal Chem. J. 85 (2008) 830-836. doi:10.1094/CCHEM-85-6-0830.

[31] Y. Ai, J. Medic, H. Jiang, D. Wang, J. Jane, Starch characterization and ethanol production of sorghum, J. Agric. Food Chem. 59 (2011) 7385-7392. doi:10.1021/jf2007584.

[32] A. Sluiter, B. Hames, R. Ruiz, C. Scarlata, J. Sluiter, D. Templeton, Determination of ash in biomass: laboratory analytical procedure (LAP), 2005. National Renewable Energy Laboratory Golden, CO

[33] A. Sluiter, B. Hames, R. Ruiz, C. Scarlata, J. Sluiter, D. Templeton, D. Crocker, Determination of structural carbohydrates and lignin in biomass, 2008. National Renewable Energy Laboratory Golden, CO

[34] H. Linskens, J. Jackson, (Ed) Analysis of plant waste materials, 2013. Springer.

[35] R.S. Fukushima, R.D. Hatfield, Extraction and Isolation of lignin for utilization as a standard to determine lignin concentration using the acetyl bromide spectrophotometric method, J. Agric. Food Chem. 49 (2001) 3133-3139. doi:10.1021/jf010449r. 
[36] D. Greetham, T. Wimalasena, D.W.M. Kerruish, S. Brindley, R.N. Ibbett, R.L. Linforth, G. Tucker, T.G. Phister, K.A. Smart, Development of a phenotypic assay for characterisation of ethanologenic yeast strain sensitivity to inhibitors released from lignocellulosic feedstocks, J. Ind. Microbiol. Biotechnol. 41 (2014) 931-945. doi:10.1007/s10295-014-1431-6.

[37] C.E. Oshoma, D. Greetham, E.J. Louis, K.A. Smart, T.G. Phister, C. Powell, C. $\mathrm{Du}$, Screening of non- Saccharomyces cerevisiae strains for tolerance to formic acid in bioethanol fermentation, PLoS One 10 (2015) e0135626. doi:10.1371/journal.pone.0135626.

[38] A. Zaky, D. Greetham, E. Louis, G. Tucker, C. Du, A new isolation and evaluation method for marine-derived yeast spp. with potential applications in industrial biotechnology, J. Microbiol. Biotechnol. 26 (2016) 1891-1907.

[39] C. Powell, D. Quain, K.S. Research, The impact of brewing yeast cell age on fermentation performance, attenuation and flocculation, FEMS Yeast Res. (2003).

[40] J. Taylor, J. Dewar, Developments in sorghum food technologies, Adv. Food Nutr. Res., 43 (2001) 217-264.

[41] K. Sriroth, R. Chollakup, S Chotineeranat, K. Piyachomkwan, C. Oates, Processing of cassava waste for improved biomass utilization, Bioresour. Technol. . 71 (2000) 63-69.

[42] A. Pandey, C. Soccol, P. Nigam, VT Soccol, L. Vandenberghe, R. Mohan, Biotechnological potential of agro-industrial residues. II: cassava bagasse, Bioresour. Technol. 74 (2000) 81-87.

[43] RS Bhatty, Physicochemical properties of roller-milled barley bran and flour, Cereal Chem. 70 (1993) 397.

[44] E. Arendt, E. Zannini, Cereal grains for the food and beverage industries, (2013). Woodhead Publishing.

[45] S.P. Choi, M.T. Nguyen, S.J. Sim, Enzymatic pretreatment of Chlamydomonas reinhardtii biomass for ethanol production, Bioresour. Technol. 101 (2010) 53305336. doi:10.1016/j.biortech.2010.02.026.

[46] C. Huang, J. He, Y. Wang, D. Min, Q. Yong, Q. Associating cooking additives with sodium hydroxide to pretreat bamboo residues for improving the enzymatic saccharification and monosaccharides production. Bioresour. Technol., (2015) 193, 142-149.

[47] B. Yang, C.E. Wyman, Pretreatment: the key to unlocking low-cost cellulosic ethanol, Biofuels, Bioprod. Biorefining. 2 (2008) 26-40. doi:10.1002/bbb.49.

[48] T. Nguyen, C. Cai, R Kumar, Overcoming factors limiting high-solids fermentation of lignocellulosic biomass to ethanol, in: Proc. Natl. Acad. Sci., 2017: p. 201704652.

[49] S. Xue, N. Uppugundla, M.J. Bowman, D. Cavalier, L. Da Costa Sousa, B. E Dale, V. Balan, Sugar loss and enzyme inhibition due to oligosaccharide accumulation during high solids-loading enzymatic hydrolysis, Biotechnol. Biofuels. 8 (2015) 195. doi:10.1186/s13068-015-0378-9.

[50] A.I. Ávila-Lara, J.N. Camberos-Flores, J.A. Mendoza-Pérez, S.R. MessinaFernández, C.E. Saldaña-Duran, E.I. Jimenez-Ruiz, L.M. Sánchez-Herrera, J.A. Pérez-Pimienta, Optimization of alkaline and dilute acid pretreatment of agave bagasse by response surface methodology, Front. Bioeng. Biotechnol. 3 (2015). doi:10.3389/fbioe.2015.00146.

[51] T. Marzialetti, M.B. Valenzuela Olarte, C. Sievers, T.J.C. Hoskins, P.K. Agrawal, 
C.W. Jones, Dilute acid hydrolysis of Loblolly Pine: A comprehensive approach, Ind. Eng. Chem. Res. 47 (2008) 7131-7140. doi:10.1021/ie800455f.

[52] J.M. Oliva, F. Sáez, I. Ballesteros, A. González, M.J. Negro, P. Manzanares, M. Ballesteros, Effect of lignocellulosic degradation compounds from steam explosion pretreatment on ehanol fermentation by thermotolerant yeast Kluyveromyces marxianus, in: Biotechnol. Fuels Chem., Humana Press, Totowa, NJ, 2003: pp. 141-153. doi:10.1007/978-1-4612-0057-4_11.

[53] M.B. Tasić, B. V. Konstantinović, M.L. Lazić, V.B. Veljković, The acid hydrolysis of potato tuber mash in bioethanol production, Biochem. Eng. J. 43 (2009) 208-211. doi:10.1016/j.bej.2008.09.019.

[54] L.K. Stakhorskaya, N.I. Kats., Effect of hydroxymethylfurfural on yeast grown in continuous cultures., Trans. Vses. Nauch-Issled. Inst. Gidroliz. Rast. Mater. 17 (1968) 97.

[55] K. Voordeckers, D. De Maeyer, E. van der Zande, M.D. Vinces, W. Meert, L. Cloots, O. Ryan, K. Marchal, K.J. Verstrepen, Identification of a complex genetic network underlying Saccharomyces cerevisiae colony morphology, Mol. Microbiol. 86 (2012) 225-239. doi:10.1111/j.1365-2958.2012.08192.x.

[56] B. Bochner, P. Gadzinski, E Panomitros, Phenotype microarrays for highthroughput phenotypic testing and assay of gene function, Genome Res. 11 (2001) 1246-1255.

[57] E.T. Kostas, D.A. White, C. Du, D.J. Cook, Selection of yeast strains for bioethanol production from UK seaweeds, J. Appl. Phycol. 28 (2016) 1427-1441. doi:10.1007/s10811-015-0633-2.

[58] S. Nonklang, B. Abdel-Banat, K Cha-aim, N. Moonjai, H. Hoshida, S. Limtong, M. Yamada, R. Akada, High-temperature ethanol fermentation and transformation with linear DNA in the thermotolerant yeast Kluyveromyces marxianus DMKU31042, Appl. Environ. Microbiol. 74 (2008) 7514-7521.

[59] Y. Oda, K. Nakamura, Production of ethanol from the mixture of beet molasses and cheese whey by a 2-deoxyglucose-resistant mutant of Kluyveromyces marxianus, FEMS Yeast Res. 9 (2009) 742-748. doi:10.1111/j.15671364.2009.00519.x.

[60] B. Erdei, Z. Barta, B. Sipos, K. Réczey, M. Galbe, G. Zacchi, Ethanol production from mixtures of wheat straw and wheat meal, Biotechnol. Biofuels. 3 (2010) 16. doi:10.1186/1754-6834-3-16.

[61] FAO report http://www.fao.org/faostat/en/\#rankings/countries_by_commodity. (Accessed Feb 21, 2019).

[62] D Humbird, R Davis, L Tao, C Kinchin, D Hsu, A, Aden. Process design and economics for biochemical conversion of lignocellulosic biomass to ethanol: diluteacid pretreatment and enzymatic hydrolysis of corn stover. National Renewable Energy Laboratory, 2011 May. Report No.: NREL/TP-5100- 47764. Contract No.: DE-AC36-08GO28308. Sponsored by the US Department of Energy.

[63] P. U. Chukwu, A.H. Isa, J.O. Ojosu, J.S. Olayande, Energy Consumption in transport sector in Nigeria: Current situation and ways forward, J. Energy Technol. Policy 5 (2015), 75-83. 
List of Tables

Table 1: Yeast strains employed in this study

\begin{tabular}{lll}
\hline STRAIN & OTHER NAMES \\
\hline Saccharomyces cerevisiae & CBS 1200; \\
NCYC 2592 & ATCC 4126 \\
Scheffersomyces stipitis & N/A \\
Wickerhamomyces anomalous & N/A & \\
Kluyveromyces marxianus & N/A & \\
Saccharomyces cerevisiae & ATCC 44774; DBY \\
NCYC 1383 & 747 \\
Saccharomyces pastorianus & N/A \\
Saccharomyces cerevisiae & N/A \\
NCYC 1119 & \\
Candida arabinofermentans & CBS 8468 \\
NCYC 2916 & NRRL YB-2248 \\
\hline
\end{tabular}


Table 2

Table 2: Compositional analysis of sorghum brans (w/w)

\begin{tabular}{lcc}
\hline Component & $\begin{array}{c}\text { White sorghum } \\
\text { Bran (\%) }\end{array}$ & $\begin{array}{c}\text { Red sorghum } \\
\text { bran (\%) }\end{array}$ \\
\hline Moisture content & $6.81 \pm 0.21^{\mathrm{a}}$ & $6.29 \pm 0.17^{\mathrm{b}}$ \\
Ash & $1.83 \pm 0.25^{\mathrm{a}}$ & $1.45 \pm 0.19^{\mathrm{b}}$ \\
${ }^{\jmath}$ Cellulose & $7.48 \pm 0.58^{\mathrm{a}}$ & $5.67 \pm 0.43^{\mathrm{b}}$ \\
${ }^{\wedge}$ Hemicellulose & $5.36 \pm 0.05^{\mathrm{a}}$ & $5.21 \pm 0.20^{\mathrm{a}}$ \\
Starch & $49.66 \pm 0.86^{\mathrm{a}}$ & $52.96 \pm 1.43^{\mathrm{b}}$ \\
Lignin & $6.73 \pm 0.64^{\mathrm{a}}$ & $10.53 \pm 0.8^{\mathrm{b}}$ \\
Protein & $15.61 \pm 0.56^{\mathrm{a}}$ & $16.94 \pm 0.13^{\mathrm{b}}$ \\
Lipid & $2.86^{\mathrm{j}} \pm 0.09^{\mathrm{a}}$ & $3.66^{\mathrm{k}} \pm 0.13^{\mathrm{b}}$ \\
TOTAL & 96.3 & 102.71 \\
\hline
\end{tabular}

-Monomeric sugars after strong acid hydrolysis

Glucose

$57.96 \pm 5.07^{\mathrm{a}}$

$59.87 \pm 2.14^{\mathrm{a}}$

Xylose

$2.96 \pm 0.08^{b}$

$3.05 \pm 0.05^{b}$

Arabinose

$$
3.13 \pm 0.89^{\mathrm{c}} \quad 2.88 \pm 0.05^{\mathrm{c}}
$$

Mannose

$4.98 \pm 0.28^{\mathrm{d}}$ $4.69 \pm 0.21^{\mathrm{d}}$

-Determined from total carbohydrate analysis; ${ }^{3}$ cellulose $=$ (total glucose-starch glucose + mannose $) \times 0.9 ;{ }^{\wedge}$ hemicellulose $=($ xylose + arabinose $) \times 0.88$.

Values are means $(n=3) \pm S D$; values within rows bearing different alphabet superscripts are significantly different $(\mathrm{p}<0.05)$. 
Table 3: Sugars liberated from sorghum bran via dilute acid hydrolysis.

\begin{tabular}{|c|c|c|c|c|c|c|}
\hline \multirow{2}{*}{ Sample } & \multirow{2}{*}{$\begin{array}{l}\text { Time } \\
(\min )\end{array}$} & \multirow{2}{*}{ Treatment } & \multicolumn{4}{|c|}{ Concentration $(\mathrm{g} / \mathrm{L})$} \\
\hline & & & Glucose & Xylose & Maltose & Arabinose \\
\hline \multirow{6}{*}{$\begin{array}{l}\text { White } \\
\text { sorghum } \\
\text { bran }\end{array}$} & 15 & $1 \% \mathrm{H}_{2} \mathrm{SO}_{4}$ & $27.37 \pm 4.09$ & $1.2 \pm 0.21$ & $2.58 \pm 0.08$ & $2.04 \pm 0.19$ \\
\hline & & $3 \% \mathrm{H}_{2} \mathrm{SO}_{4}$ & $32.24 \pm 7.27$ & $1.1 \pm 0.02$ & $1.60 \pm 0.04$ & $1.96 \pm 0.00$ \\
\hline & 30 & $1 \% \mathrm{H}_{2} \mathrm{SO}_{4}$ & $28.07 \pm 0.96$ & $1.06 \pm 0.10$ & $1.45 \pm 0.07$ & $2.01 \pm 0.10$ \\
\hline & & $3 \% \mathrm{H}_{2} \mathrm{SO}_{4}$ & $34.53 \pm 8.04$ & $1.15 \pm 0.02$ & $1.38 \pm 0.02$ & $1.92 \pm 0.10$ \\
\hline & 15 & $1 \% \mathrm{HNO}_{3}$ & $25.77 \pm 1.15$ & $3.11 \pm 0.41$ & $1.12 \pm 0.04$ & $2.17 \pm 0.40$ \\
\hline & 30 & $1 \% \mathrm{HNO}_{3}$ & $26.34 \pm 1.05$ & $2.15 \pm 1.57$ & $1.00 \pm 0.02$ & $2.13 \pm 0.40$ \\
\hline \multirow{6}{*}{$\begin{array}{l}\text { Red } \\
\text { sorghum } \\
\text { bran }\end{array}$} & 15 & $1 \% \mathrm{H}_{2} \mathrm{SO}_{4}$ & $26.48 \pm 1.06$ & $0.75 \pm 0.05$ & $2.22 \pm 0.76$ & $1.66 \pm 0.10$ \\
\hline & & $3 \% \mathrm{H}_{2} \mathrm{SO}_{4}$ & $32.17 \pm 6.05$ & $0.79 \pm 0.01$ & $4.18 \pm 0.16$ & $2.13 \pm 0.60$ \\
\hline & 30 & $1 \% \mathrm{H}_{2} \mathrm{SO}_{4}$ & $27.11 \pm 4.84$ & $0.75 \pm 0.00$ & $1.30 \pm 0.15$ & $1.95 \pm 0.00$ \\
\hline & & $3 \% \mathrm{H}_{2} \mathrm{SO}_{4}$ & $31.68 \pm 5.71$ & $4.53 \pm 0.32$ & $1.56 \pm 0.08$ & $3.63 \pm 2.70$ \\
\hline & 15 & $1 \% \mathrm{HNO}_{3}$ & $28.25 \pm 0.33$ & $2.51 \pm 0.04$ & $1.04 \pm 0.04$ & $1.76 \pm 0.00$ \\
\hline & 30 & $1 \% \mathrm{HNO}_{3}$ & $26.13 \pm 1.52$ & $2.46 \pm 0.00$ & $0.81 \pm 0.00$ & $1.98 \pm 0.00$ \\
\hline
\end{tabular}

Values are means $(n=3) \pm S D$. 
Table 4: Inhibitor concentrations in sorghum bran hydrolysates.

\begin{tabular}{|c|c|c|c|c|c|}
\hline \multirow{2}{*}{ Sample } & \multicolumn{5}{|c|}{ Concentration (mg/L) } \\
\hline & $\mathrm{HMF}$ & Furfural & Vanillin & Ferulic Acid & Acetic Acid \\
\hline WBDAH & $5.05 \pm 0.50^{\mathrm{a}}$ & $4.27 \pm 0.11^{\mathrm{a}}$ & $5.62 \pm 0.91^{\mathrm{a}}$ & $19.64 \pm 1.47^{\mathrm{a}}$ & $22.37 \pm 1.15$ \\
\hline WBEH & $1.18 \pm 0.18^{\mathrm{b}}$ & $0.33 \pm 0.06^{b}$ & ND & $1.98 \pm 0.21^{\mathrm{b}}$ & $39.94 \pm 3.89$ \\
\hline RBDAH & $5.93 \pm 1.01^{\mathrm{c}}$ & $5.95 \pm 0.71^{\mathrm{c}}$ & $9.67 \pm 1.13^{\mathrm{b}}$ & $17.12 \pm 2.05^{\mathrm{c}}$ & $30.25 \pm 2.76$ \\
\hline RBEH & $1.04 \pm 0.23^{b}$ & ND & ND & ND & $42.89 \pm 5.42$ \\
\hline
\end{tabular}


Table 5: Ethanol concentrations obtained from yeast fermentation when using sorghum bran hydrolysates as a substrate

${ }^{a-k}$ Values within rows bearing different alphabet superscripts are significantly different. Ethanol yield was expressed as a percentage of theoretical maximum yield.

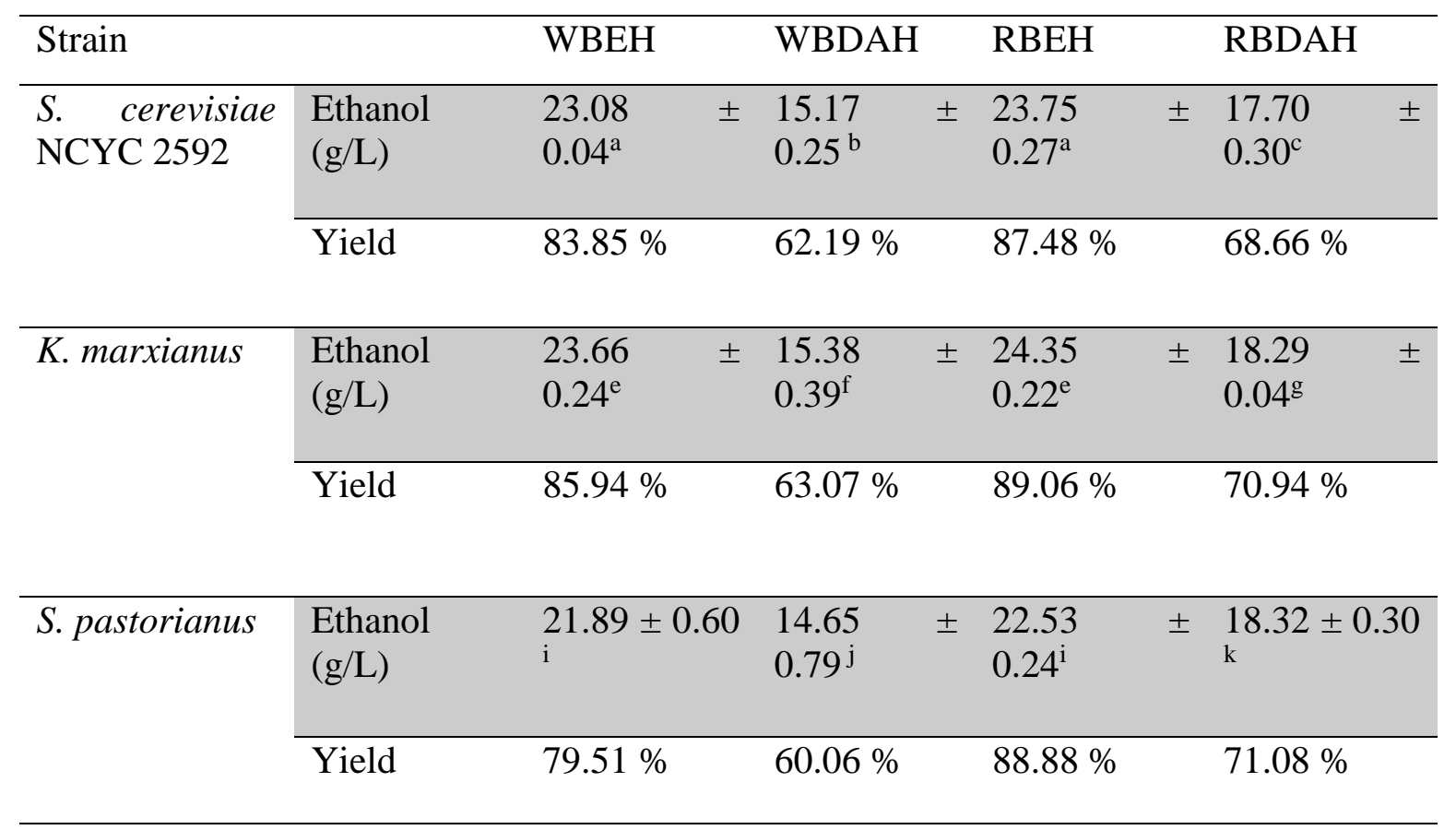




\section{List of Figures}

Figure 1

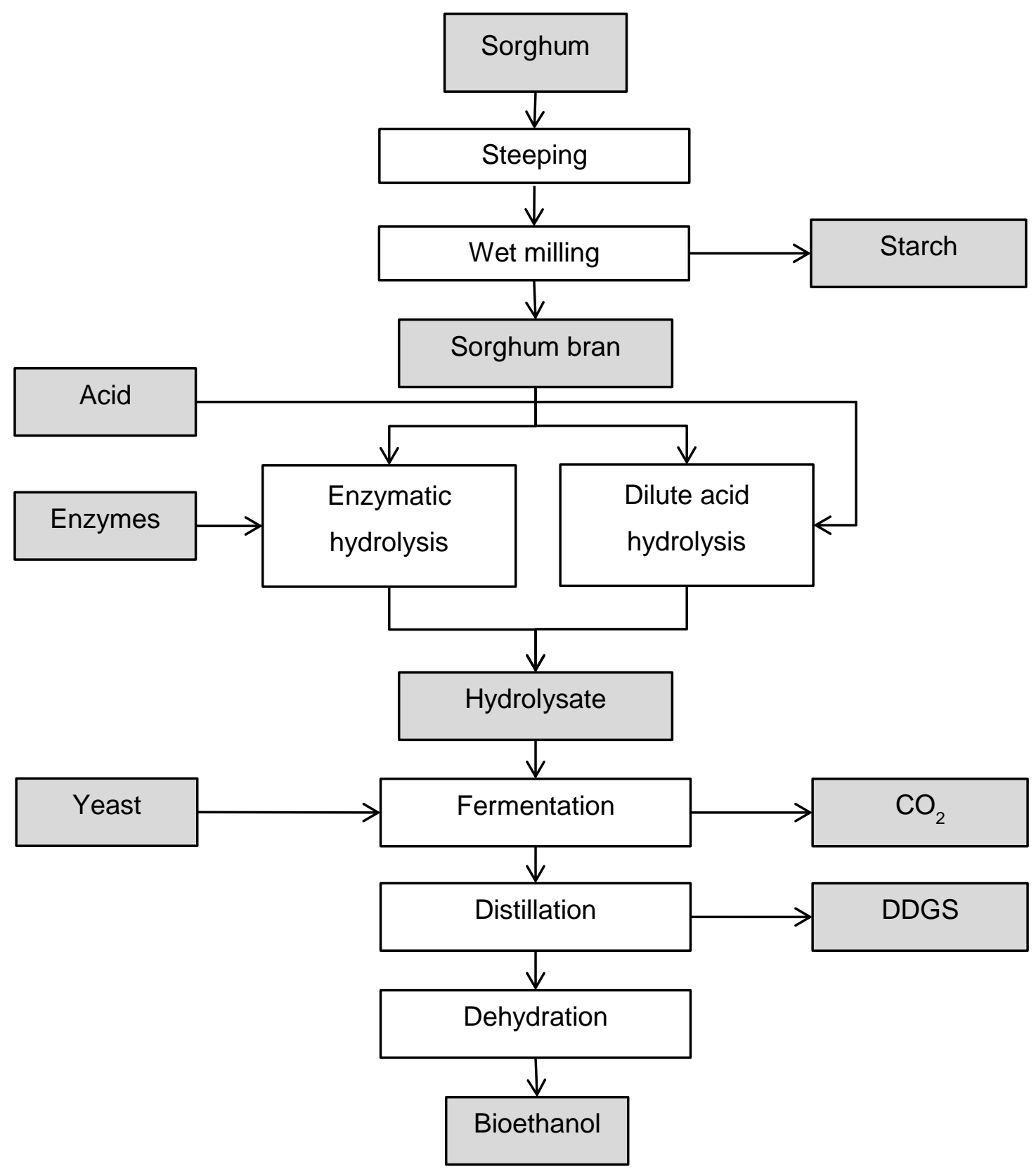

Figure 1: Schematic diagram of a sorghum based biorefining process. DDGS: Distiller's Dried Grains with Solubles. 
Figure 2

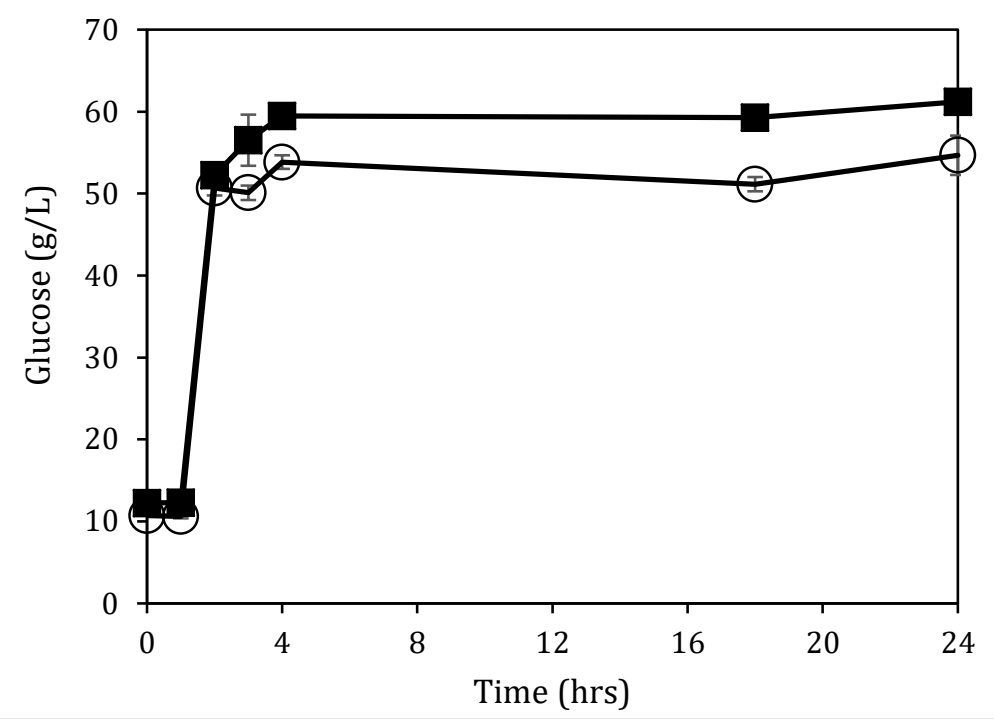

Figure 2: Glucose concentration of sorghum bran hydrolysate (filled square: red sorghum bran; open circle: white sorghum bran) from enzymatic hydrolysis. Values are means \pm standard deviations $(\mathrm{n}=3)$. 
Figure 3

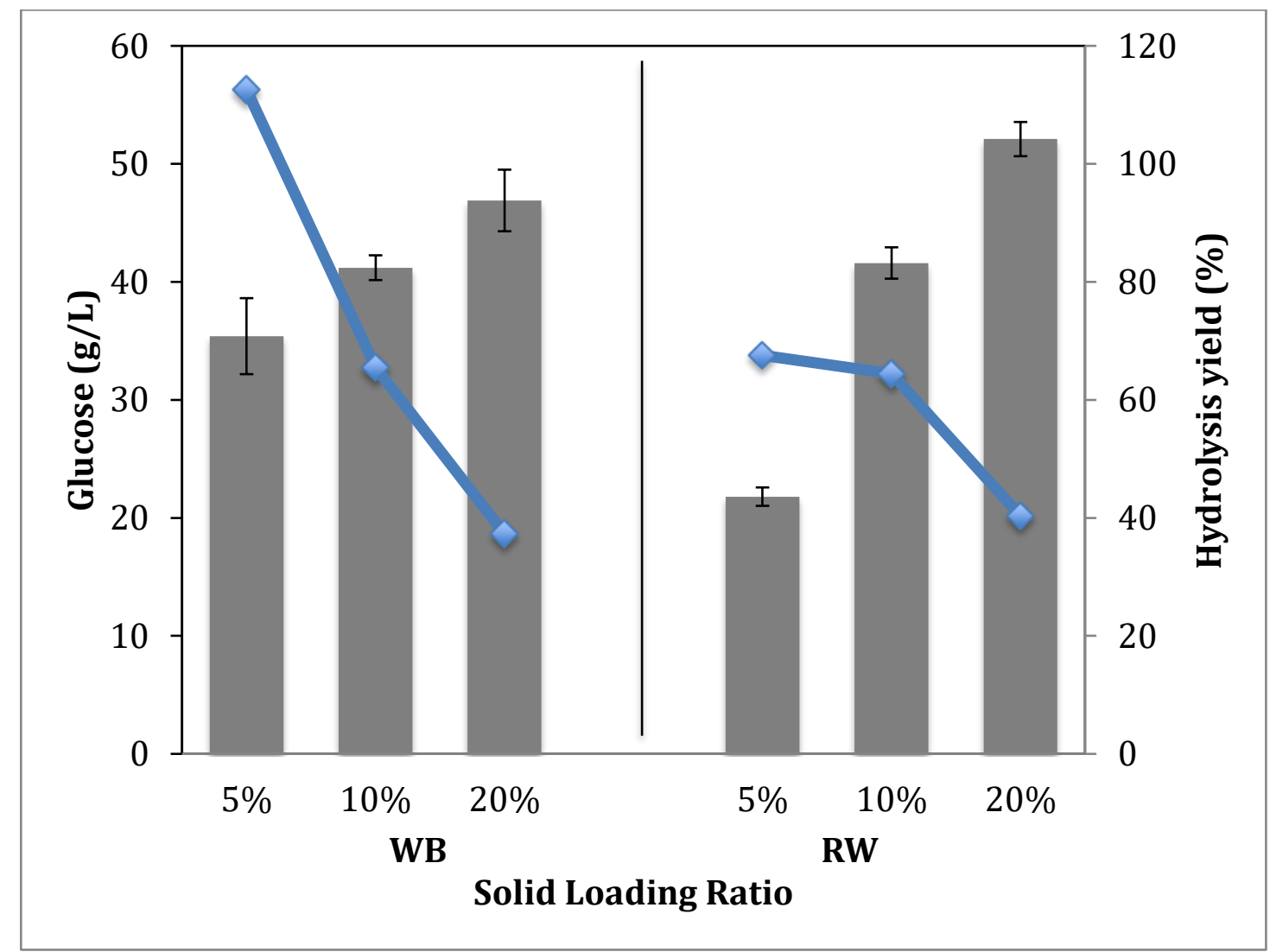

Figure 3: The effect of loading ratio on bran conversion efficiency in diluted $\mathrm{H}_{2} \mathrm{SO}_{4}$ hydrolysis at $121^{\circ} \mathrm{C}$ for $15 \mathrm{~min}$. The blue lines represent glucose hydrolysis yield. Grey bars show glucose concentrations in the hydrolysate $(\mathrm{g} / \mathrm{L})$. Values are means \pm standard deviations $(n=3)$. 
Figure 4

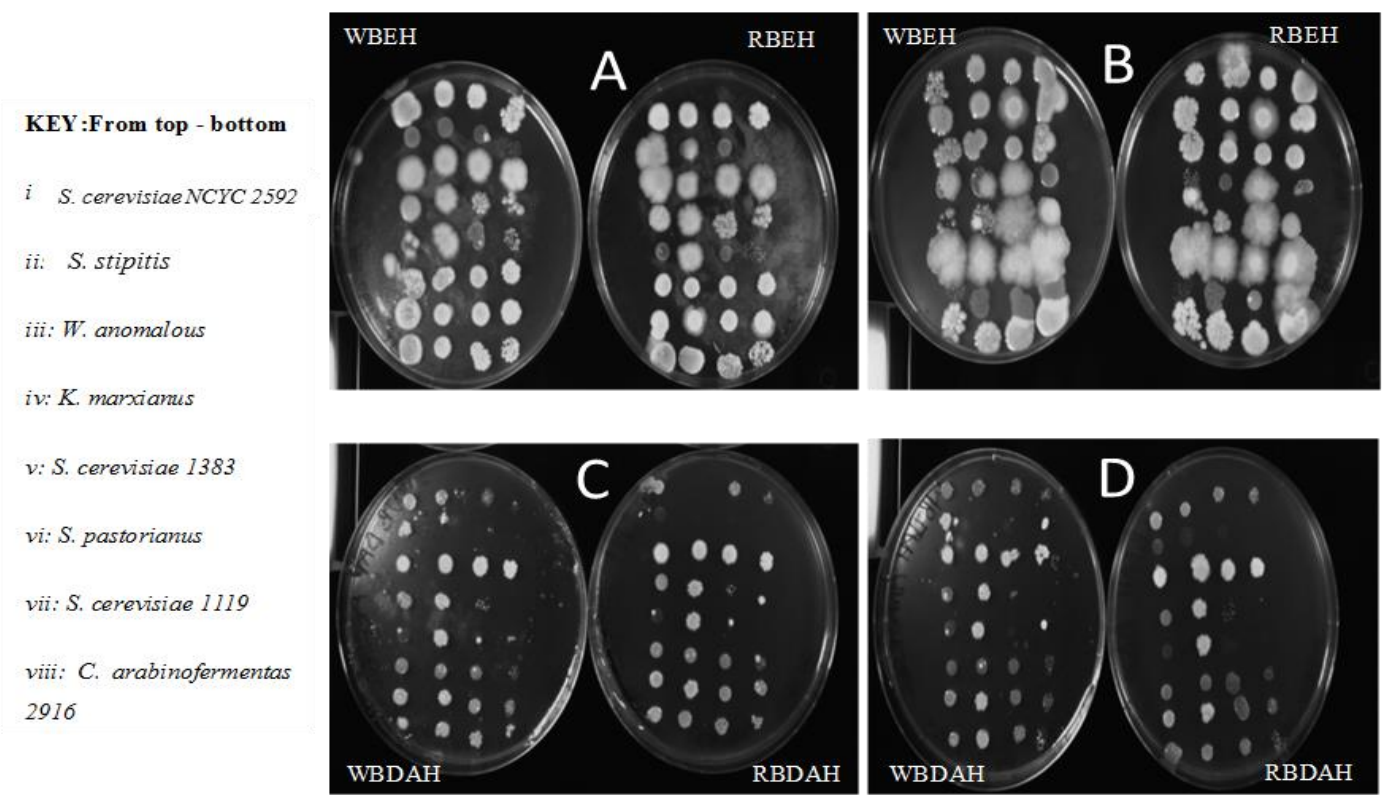

Figure 4: Spot-plate screening tests showing typical growth pattern of eight yeast strains when grown on agar plates prepared from four different types of sorghum bran hydrolysates and viewed under UV light with a GelDoc Imaging system. A and C: Aerobic incubation; B and D: Anaerobic incubation. A and B: Enzymatic hydrolysis; C and D: Dilute Acid Hydrolysis. Spots comprise yeast cells in dilutions of $\mathrm{OD}_{600}=1$ stock from L-R: $10^{-1}-10^{-4}$. 
Figure 5.

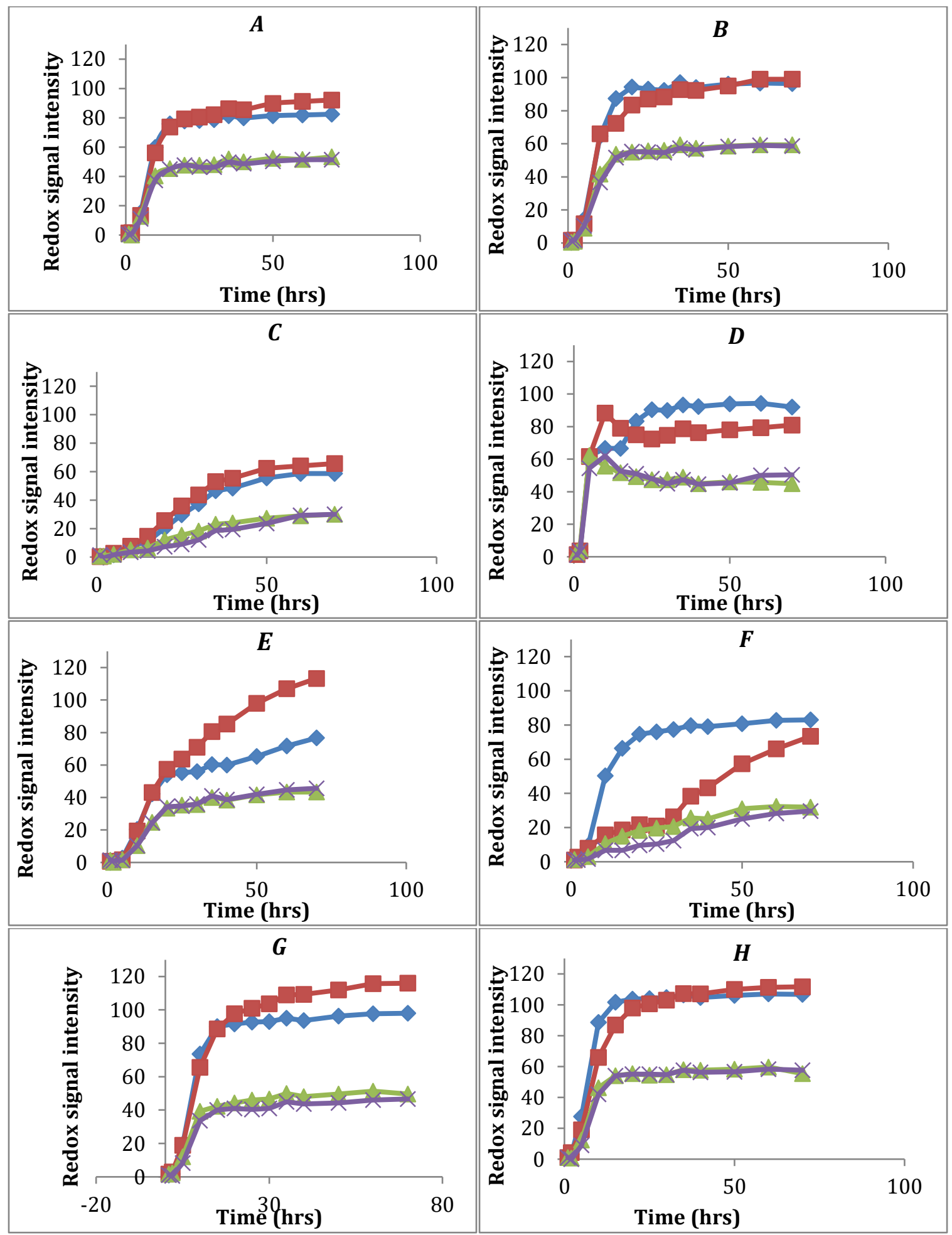

Figure 5: Phenotypic microarray analysis showing metabolic activity of 8 yeast strains, as judged by redox signal intensity, when cultivated on four sorghum bran hydrolysates, anaerobically for $72 \mathrm{hr}$. A, Saccharomyces cerevisiae NCYC 2592; B, Candida arabinofermentas; C, 
Scheffersomyces stipites; D, Wickerhamomyces anomalous; E, Kluyveromyces marxianus; F, S. cerevisiae NCYC 1383; G, Saccharomyces pastorianus; and H, S. cerevisiae NCYC 1119. Blue diamond: White sorghum bran enzymatic hydrolysate; Red square: Red sorghum bran enzymatic hydrolysate; Green triangle: White sorghum bran dilute acid hydrolysate; purple cross: Red sorghum bran dilute acid hydrolysate. 
Figure 6
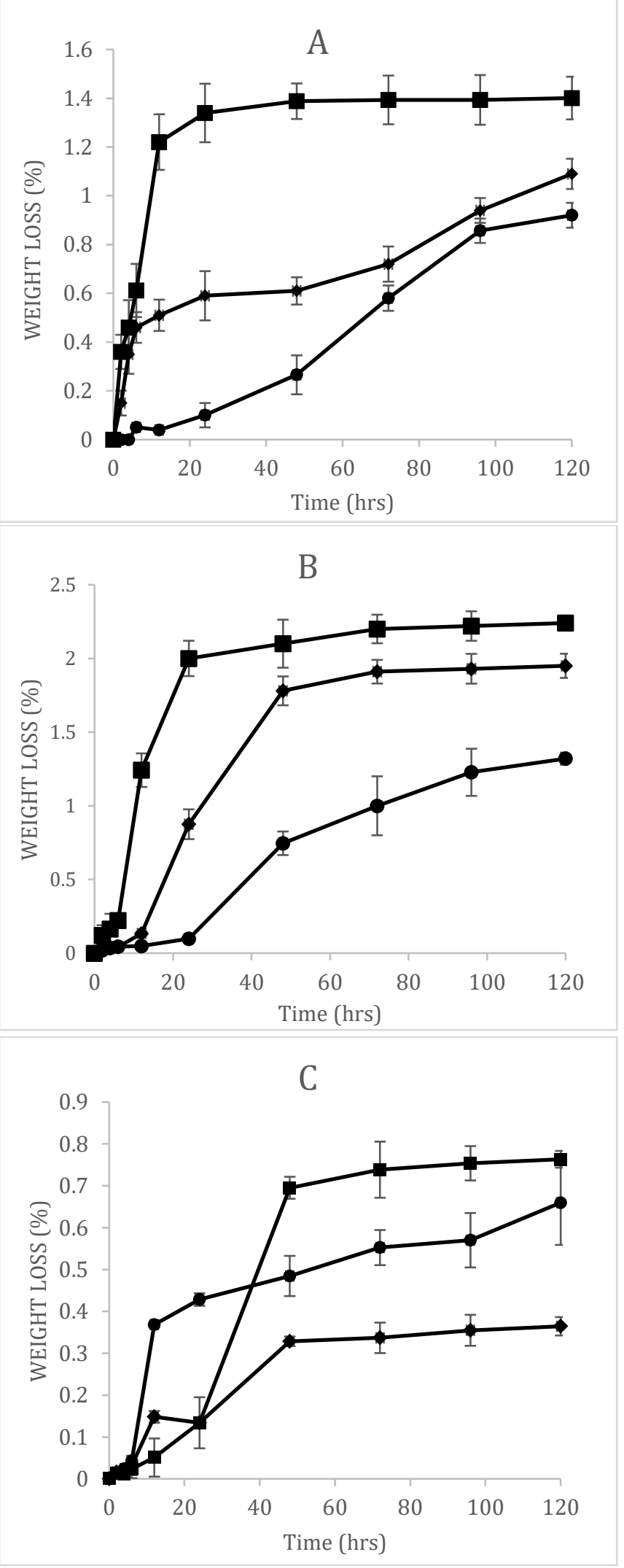


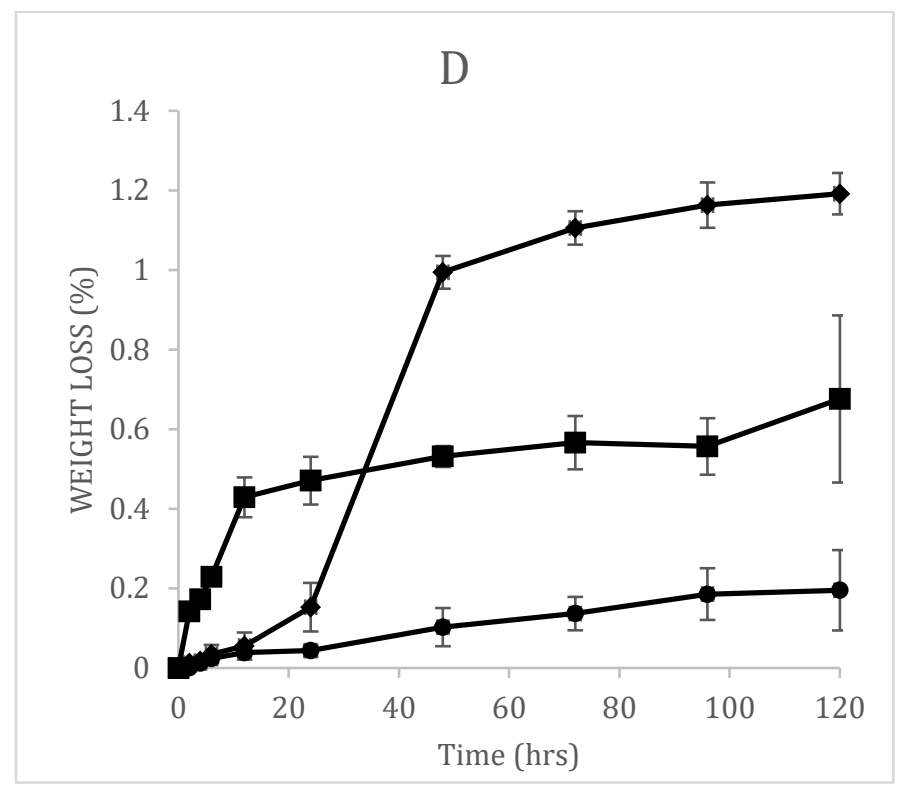

Figure 6: Weight loss trends for mini-fermentations of sorghum bran hydrolysates and a synthetic medium by three different yeast species. Square: S. cerevisiae NCYC2592; Diamond: $K$. marxianus; Circle: $S$. pastorianus. A $=\mathrm{WBEH}$; B $=\mathrm{RBEH}$; C $=\mathrm{WBDAH}$; $\mathrm{D}=\mathrm{RBDAH}$. Values are means \pm standard deviations $(\mathrm{n}=3)$. 
Figure 7

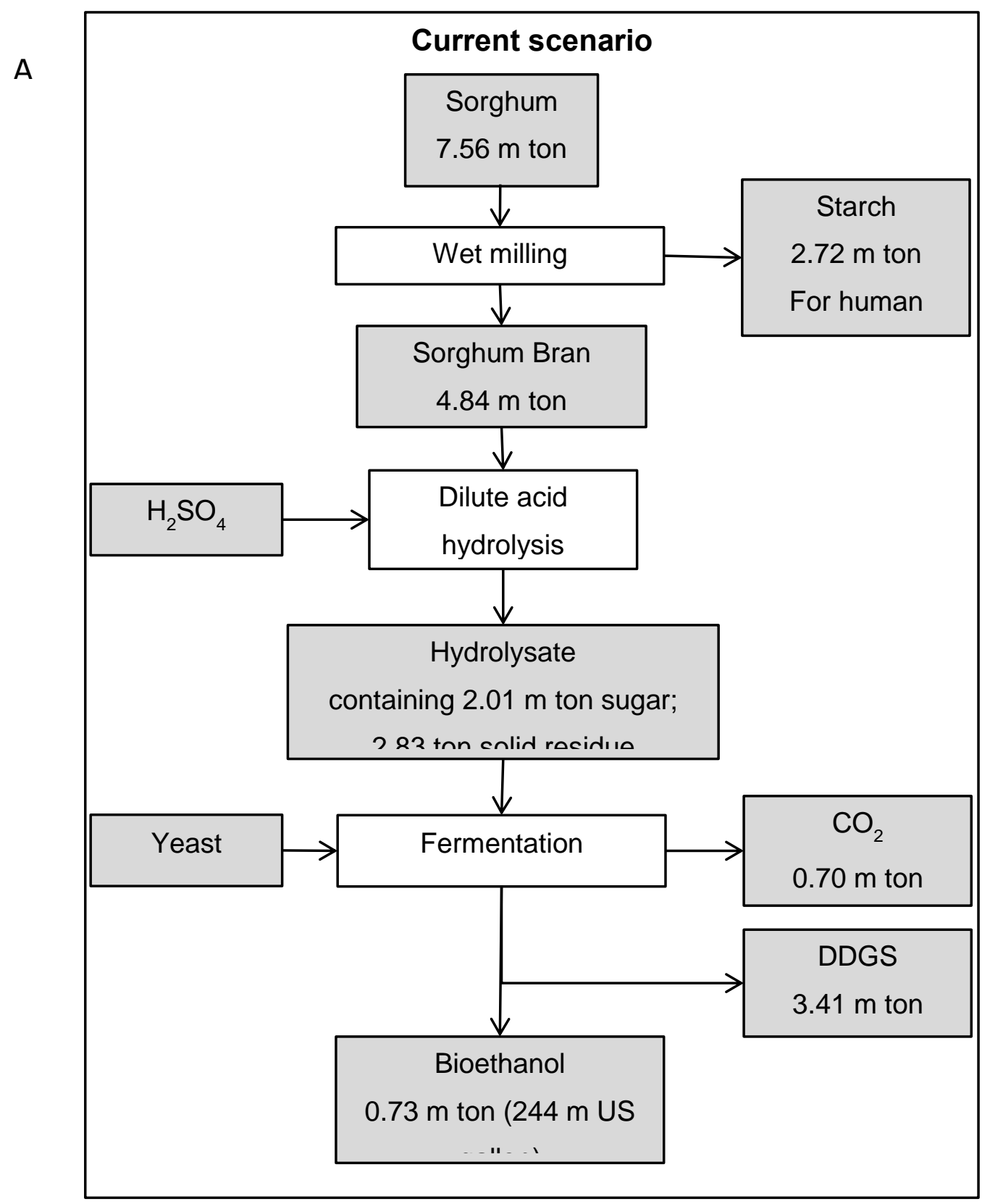




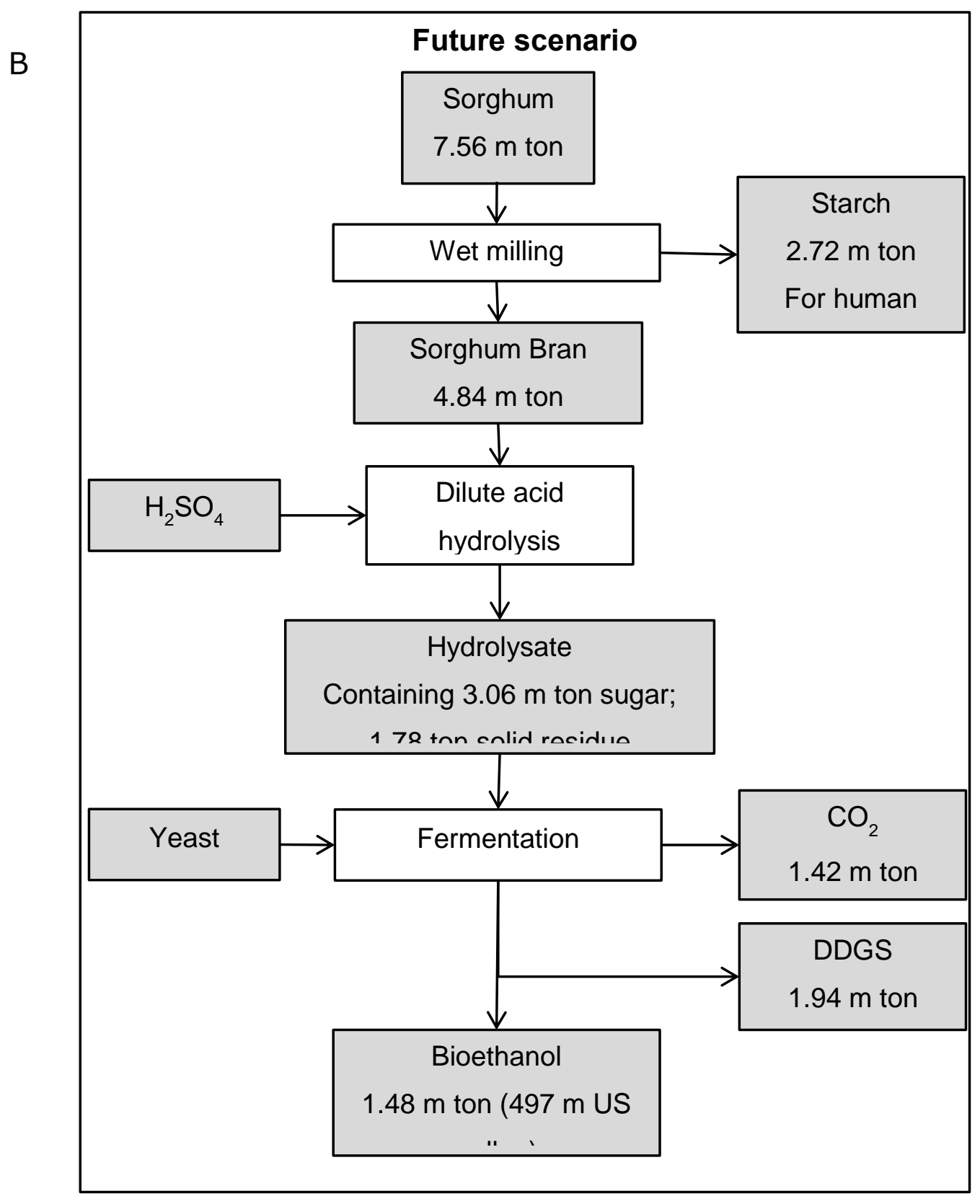

Figure 7: A schematic diagram showing mass balance of bioethanol production potential in Nigeria using sorghum milling waste as the substrate. A: Current scenario, based on the current hydrolysis and fermentation yield obtained in this study. B: Future scenario, based on the assumption of potential hydrolysis $(90 \%)$ and fermentation yield (95\%). The mass introduced by $\mathrm{H}_{2} \mathrm{SO}_{4}$ and Yeast was not considered. The water contents in the sorghum, and DDGS were not considered. 